\title{
Dilatometric Study of the Precipitation Kinetics in Cu-Al-Ni Shape Memory Alloys
}

\author{
V. Recarte, R.B. Pérez-Sáez, M.L. Nó* and J. San Juan \\ Departamento de Física de la Materia Condensada, Facultad de Ciencias, Universidad del País Vasco, \\ Apdo. 644, 48080 Bilbao, Spain \\ * Departamento de Física Aplicada II, Facultad de Ciencias, Universidad del País Vasco, Apdo. 644, \\ 48080 Bilbao, Spain
}

\begin{abstract}
The maximum working temperature in CuAINi shape memory alloys is limited by the precipitation of the stable phases that damages the good thermomechanical behaviour during the martensitic transformation. In this paper, the precipitation kinetics of the stable phases inside the metastable $\boldsymbol{B}$ phase have been studied by quenching dilatometry in a wide range of temperatures. The different phases have been characterised by scanning electronic microscopy and X-ray diffraction. Moreover, the precipitation kinetics have been analysed using a double JhonsonMhell-Avrami equation. The extrapolation of the obtained characteristic parameters allows us to predict the behaviour of the alloy at lower temperatures. Finally, the TTT curve has been obtained for both the primary precipitation and the eutectoid decomposition.
\end{abstract}

\section{INTRODUCTION}

Among the wide variety of alloys that exhibit the shape memory effect the most developed, as a consequence of their practical applications, are the nickel-titanium alloys and the copper-based alloys such as $\mathrm{Cu}-\mathrm{Zn}-\mathrm{Al}$ and $\mathrm{Cu}-\mathrm{Al}-\mathrm{Ni}[1,2]$. The $\mathrm{Cu}-\mathrm{Al}-\mathrm{Ni}$ shape memory alloys have been developed as an alternative to the classically used $\mathrm{Cu}-\mathrm{Zn}-\mathrm{Al}$ and $\mathrm{Ti}-\mathrm{Ni}$ alloys. The main interest of these alloys from a technological point of view is their possible use at temperatures near $200^{\circ} \mathrm{C}$ [3], in advantage over the $\mathrm{Cu}-\mathrm{Zn}-\mathrm{Al}$ and $\mathrm{Ti}-\mathrm{Ni}$ alloys whose maximum working temperature is limited to $100^{\circ} \mathrm{C} \mathrm{[3]} \mathrm{for} \mathrm{several}$ reasons. The main problem that must be solved to guarantee the reliability of the $\mathrm{Cu}-\mathrm{Al}-\mathrm{Ni}$ alloys at high temperatures is to determine the stability limit of both the overcooled $\beta$ and the martensite metastable phases, in order to avoid the precipitation of the stable phases. During the normal use in high temperature applications, there is a critical temperature range, around $300^{\circ} \mathrm{C}$, in which the alloy could be accidentally overheated, thus it is important to study the $\beta$ phase stability in this temperature range.

In the present work, the stability limit of the overcooled $\beta$ phase has been established by studying the precipitation kinetic curves during isothermal ageing at different temperatures between $400^{\circ} \mathrm{C}$ and $482^{\circ} \mathrm{C}$ by dilatometry. Nevertheless, the experimental study of the precipitation processes is very difficult at temperature as low as $300^{\circ} \mathrm{C}$ due to the extraordinarily long ageing time required to obtain the isothermal kinetics. In order to overcome this problem, the dilatometric curves have been analysed using a Jhonson-Mhell-Avrami equation, thus the microstructural parameters that control the precipitation process have been determined. This way, the TTT curves between $300^{\circ} \mathrm{C}$ and $482^{\circ} \mathrm{C}$ for the precipitation process of the stable phases have been obtained.

\section{EXPERIMENTAL METHODS}

Metal ingots of $\mathrm{Cu}(99.99 \%), \mathrm{Al}(99.99 \%)$ and $\mathrm{Ni}(99.97 \%)$ were melted in a high frequency induction furnace under argon atmosphere to produce an alloy ingot with a composition of $\mathrm{Cu}-13.75 \mathrm{Al}-4.95 \mathrm{Ni}$ (wt. \%), analysed by plasma emission spectrometry. A Cu-Al-Ni alloy with this composition shows a double martensitic transformation linked to $\gamma_{1}$ and $\beta_{1}^{\prime}$ martensitic phases $[4,5]$. The obtained ingot was homogenised at $1000^{\circ} \mathrm{C}$ for 6 hours under argon atmosphere. The specimen of $48 \times 6 \times 6 \mathrm{~mm}^{3}$ was obtained by cutting the ingot. 
Conventional dilatometry at a heating-cooling rate of $4^{\circ} \mathrm{C} / \mathrm{min}$ has been used to determine the transformation temperatures of the pro-eutectoid $\gamma_{1}$ phase $\left(\mathrm{T}_{\mathrm{p}}=700^{\circ} \mathrm{C}\right)$, and the temperature of the eutectoid decomposition $\alpha+\gamma_{1}\left(\mathrm{~T}_{\mathrm{e}}=575^{\circ} \mathrm{C}\right)[6]$

The precipitation kinetics during isothermal ageing has been studied using a quenching dilatometer. An ageing process has been carried out every $12.5^{\circ} \mathrm{C}$ to cover the temperature range between $400^{\circ} \mathrm{C}$ and $482^{\circ} \mathrm{C}$. Before each dilatometry measurement the sample was annealed at $900^{\circ} \mathrm{C}$ for 30 minutes and quenched in situ to the temperature at which the isothermal ageing was going to be carried out.

In order to characterise the phases that appear during the precipitation process, the evolution of the microstructure during the isothermal ageing has been observed by scanning electron microscopy (S. E. M.). This microscopy study has been performed in a sample which has undergone the quenching process in the dilatometer.

\section{EXPERIMENTAL RESULTS AND DISCUSSION}

The isothermal curves of the dilatation vs. time between $482^{\circ} \mathrm{C}$ and $400^{\circ} \mathrm{C}$ are plotted in fig. 1(a) and 1(b). They are shown in two time scales for an easier visualisation. For the same reason, the curves are normalised and vertically shifted. The curve corresponding to $450^{\circ} \mathrm{C}$ is represented in both figures for better comparison.

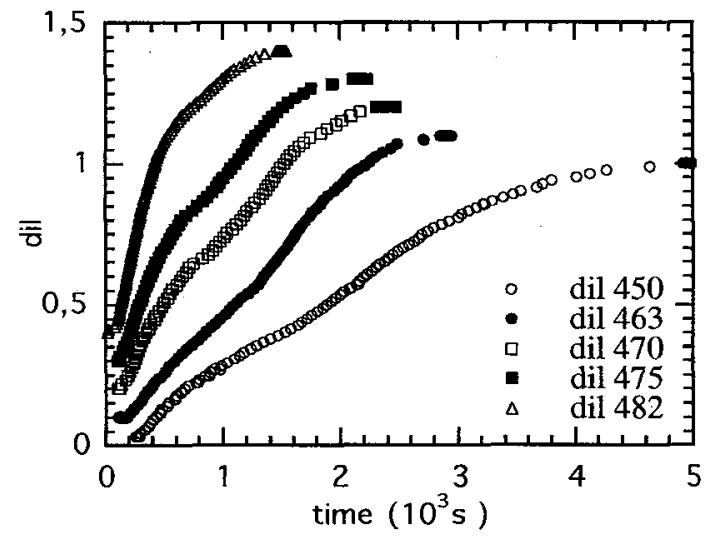

Fig. 1-a. Isothermal curves obtained by quenching dilatometry. Normalised dilatation vs. time for the temperatures between $450^{\circ} \mathrm{C}$ and $482^{\circ} \mathrm{C}$.

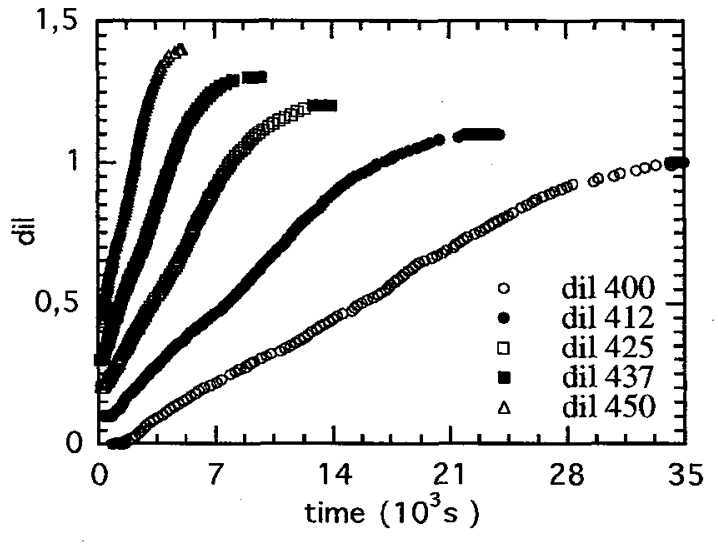

Fig. 1-b. Isothermal curves obtained by quenching dilatometry. Normalised dilatation vs. time for the temperatures between $400^{\circ} \mathrm{C}$ and $450^{\circ} \mathrm{C}$.

In all the kinetics curves, two different stages can be clearly distinguished, each one linked to one different precipitation process. Systematic S.E.M. observations have been carried out at different times along the ageing of the sample in order to identify the two different precipitation processes. Fig. 2 shows the dilatometry curve during the isothermal precipitation at $400^{\circ} \mathrm{C}$ and the S. E. M. micrographs taken at four different times :a) $50 \%$ first stage ( $3800 \mathrm{sec}$.), b) $90 \%$ first stage $(6600 \mathrm{sec}$ ), c) $50 \%$ second stage $(17700 \mathrm{sec}$.$) , and d) at the end of the whole ageing process. The primary precipitates, fig. 2(a), show a$ cuboidal shape and they are homogeneously distributed all around the matrix. The number of these precipitates increases along the evolution of their precipitation process. According to the phase diagrams proposed by R. Thomson and J. O. Edwards [7] and taking into account that the alloy is hypereutectoid, these primary precipitates have been identified as pro-eutectoid precipitates $\gamma_{1}$. This assumption has been verified by $X$-ray diffractometry [6]. It should be noted here that the $\gamma_{1}$ phase has been generally called $\gamma_{2}[8,9]$, although we will denominate it $\gamma_{1}$ phase according to the last reviews $[10,11]$.

The micrographs taken during the second stage of the ageing process (fig. 2(c) and fig. 2(d)) allow us to identify this stage as the eutectoid $\beta \leftrightarrow \gamma_{1}+\alpha$ decomposition whose typical morphology can be observed in the micrographs. This stage has been also studied by $\mathrm{X}$-ray diffraction, the peaks associated to the $\gamma_{1}$ and $\alpha$ phases are clearly identified [6]. Contrary to the primary precipitation, the eutectoid 


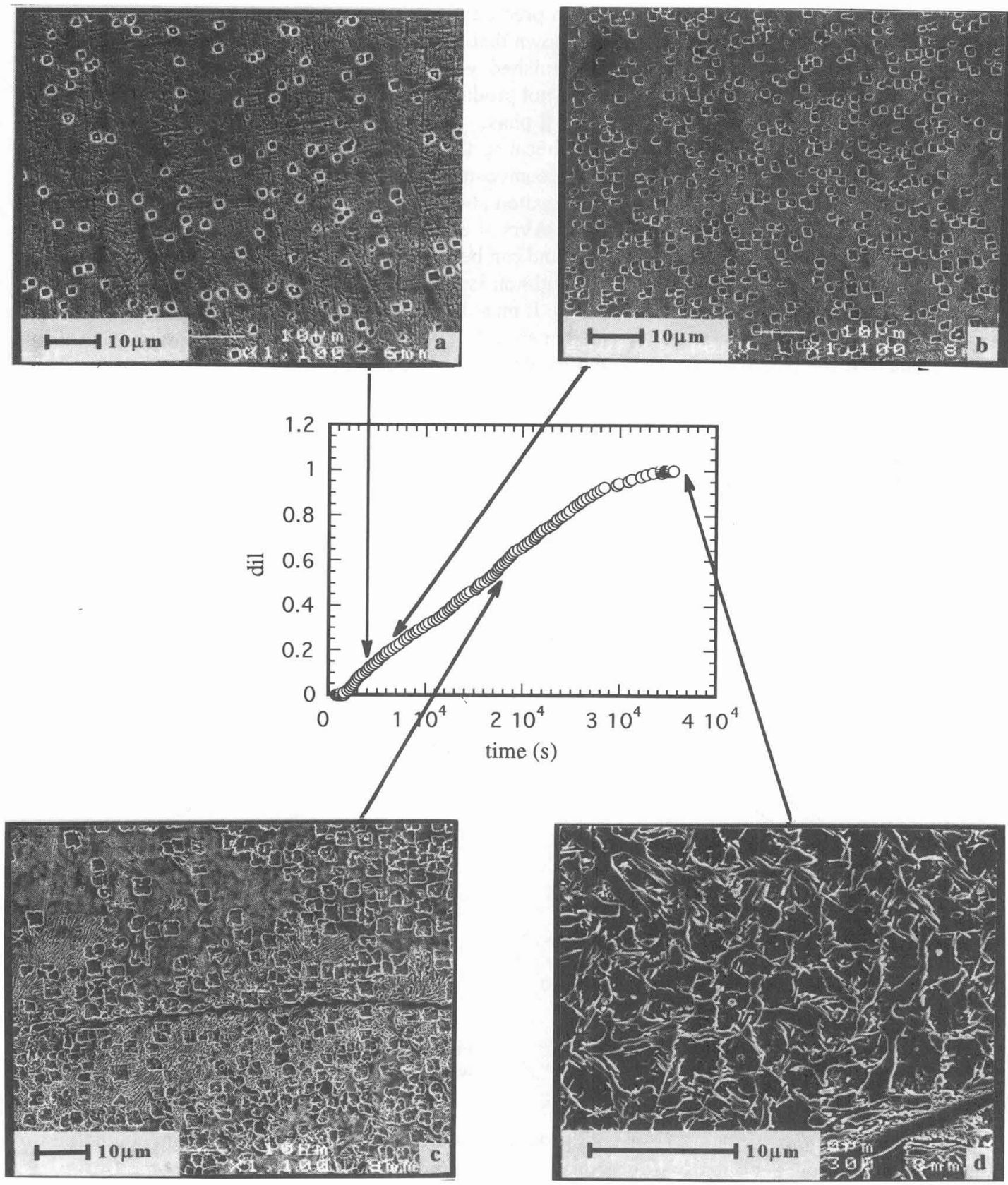

Fig. 2. S. E. M. micrographs taken at different times along the isothermal precipitation process at $400^{\circ} \mathrm{C}$. At the center of the page the experimental dilatometric curve is shown and the arrows indicate the temporal position of the micrographs:

fig. 2-a) $50 \%$ of first stage ( $3800 \mathrm{sec}$.), 2-b) $90 \%$ first stage (6600 sec.), 2-c) $50 \%$ of the second stage $(17700 \mathrm{sec}$.) and $2-\mathrm{d})$ at the end of the whole precipitation process. 
decomposition is heterogeneous and it starts to precipitate on the grain boundaries. In the micrograph 2(b) taken at $90 \%$ of the first stage, it can be shown that the eutectoid decomposition has already started although the primary precipitation has not finished yet. This overlapping of the pro-eutectoid $\gamma_{1}$ precipitation and the eutectoid decomposition is not produced in equilibrium conditions, this behaviour is linked to the high instability of the overcooled $\beta$ phase. At the end of the two stages, micrograph 2 (d), the $\gamma_{1}$ precipitates lose their cuboidal shape because the coalescence of these precipitates with the fraction of $\gamma_{1}$ phase obtained by the eutectoid decomposition.

In order to obtain more quantitative information about the precipitation processes, the dilatometry curves have been fitted with the Jhonson-Mhell-Avrami equation (J-M-A) [12,13]. This equation is very useful to explain thermally activated processes and can be applied in a lot of different circumstances [1416]. Thus, using this equation the isothermal and non isothermal kinetics of stable phases in $\mathrm{Cu}-\mathrm{Zn}-\mathrm{Al}$ shape memory alloys have been studied $[17,18]$. It must be remarked that in the precipitation process of the $\mathrm{Cu}-\mathrm{Zn}-\mathrm{Al}$ alloys only one stage has been analysed. In the case of this $\mathrm{Cu}-\mathrm{Al}-\mathrm{Ni}$ alloy, two stages must be analysed and then it is necessary to use a double $\mathrm{J}-\mathrm{M}-\mathrm{A}$ equation $[6,19]$ :

$$
y=f \times\left(1-e^{-\left(k_{1} t\right)^{n_{1}}}\right)+(1-f) \times\left(1-e^{-\left(k_{2} t\right)^{n_{2}}}\right)
$$

where $k_{i}, n_{i}$ are the characteristic parameters of both precipitation processes and $f$ is the precipitated fraction. The fit in a double J-M-A equation and the decomposition into two stages are shown in fig. 3 for the isothermal precipitation at $450^{\circ} \mathrm{C}$.

Fitting all the measured dilatometry curves, the values of the characteristics parameters $\left(n_{i}, k_{i}, f\right)$ at the different temperatures are determined. This way, taking into account that:

$$
k_{i}=k_{\mathrm{o}} e^{-E_{a}^{(i)} / k_{b} T}
$$

the apparent activation energy for each stage of precipitation can be calculated from the $k_{1}$ and $k_{2}$ values.

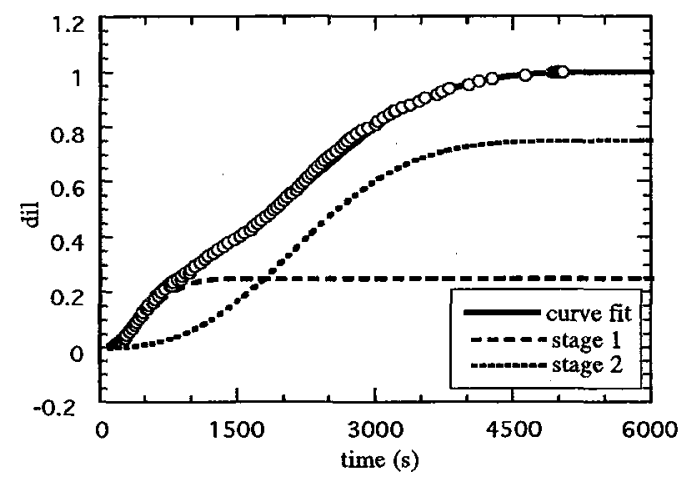

Fig. 3. Experimental data corresponding to the $450^{\circ} \mathrm{C}$ isothermal dilatometry and fitting to a double J.M.A. equation. Dashed lines are the decomposed single stages.

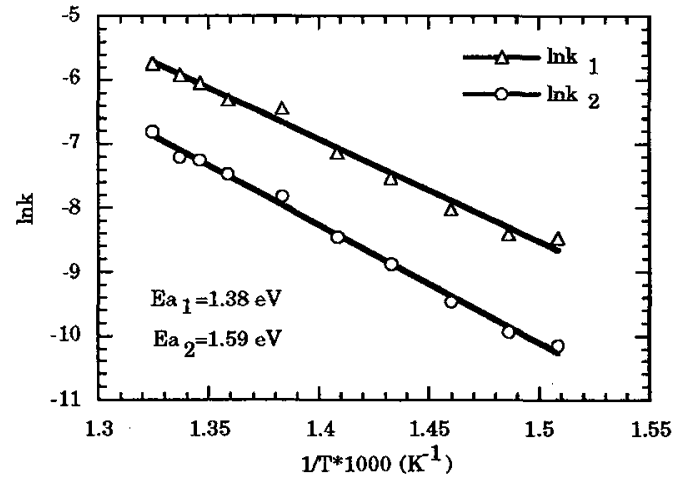

Fig. 4. Activation energies obtained from the linear regression of $\ln (k)$ versus $l / T$.

Fig. 4 shows $\ln \left(k_{i}\right)$ versus $1 / T$ for both processes as well as the fit to a straight line that allows to obtain the activation energies of the primary precipitation and the eutectoid decomposition, are $E_{a}^{(l)}=1.38 \pm 0.03 \mathrm{eV}$ and $E_{a}^{(2)}=1.59 \pm 0.03 \mathrm{eV}$ respectively.

The obtained $n_{1}$ and $n_{2}$ values have been fitted by a linear regression in order to extrapolate the kinetics at low temperatures, fig. 5(a). The exponent $n_{1}$ is temperature independent, but $n_{2}$ shows a slight increase with temperature. This increase can be linked to the change of kinetic parameters when the ageing temperature approaches the eutectoid decomposition temperature $\mathrm{Te}=575^{\circ} \mathrm{C}$. Because of this, only the $n_{2}$ values for the temperatures lower than $460^{\circ} \mathrm{C}$ have been taken for the linear fit. Fig. 5(b) shows the primary precipitation fraction $f$ versus the ageing temperature. The $f$ value remains practically constant below $450^{\circ} \mathrm{C}$, increasing when the ageing temperature approaches the eutectoid decomposition 
temperature. This is due to a decrease of the overcooling and consequently of the driving force of the eutectoid precipitation when eutectoid decomposition temperature is reached. In this way, the eutectoid fraction decreases in relation to the primary precipitation when the ageing temperature approaches the eutectoid decomposition temperature $\mathrm{Te}=575^{\circ} \mathrm{C}$. The experimental values for temperatures lower than $450^{\circ} \mathrm{C}$ have been used to extrapolate $f$ for low temperatures.

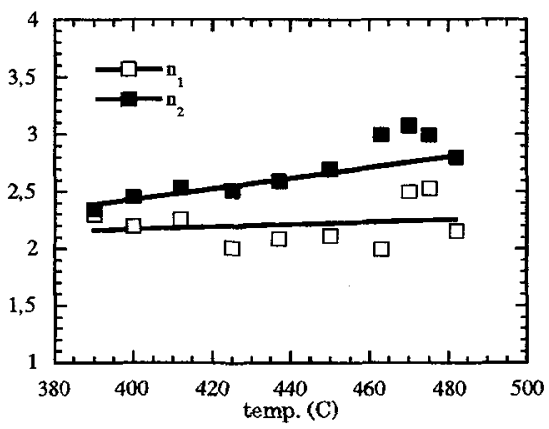

Fig. 5-a. Obtained $n_{1}$ and $n_{2}$ exponents versus temperature and the linear fits used for low temperature extrapolation.

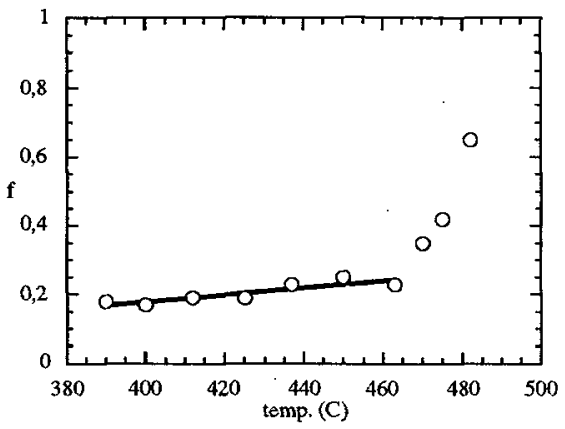

Fig. 5-b. Primary precipitation fraction $f$ and linear fit used for low temperature extrapolation.

Once the characteristic values of both kinetics have been extrapolated for low temperatures we can generate the corresponding curves between $300^{\circ} \mathrm{C}$ and $400^{\circ} \mathrm{C}$ and determine the starting precipitation times for both processes, $\beta \leftrightarrow \gamma_{1}$ and $\beta \leftrightarrow \gamma_{1}+\alpha$, at different temperatures. The TTT curves (for the $0.05 \%$ of both transformations) are shown in fig. 6 . The line is the limit of ageing time before the beginning of the precipitation and consequently the degradation of the martensitic transformation.

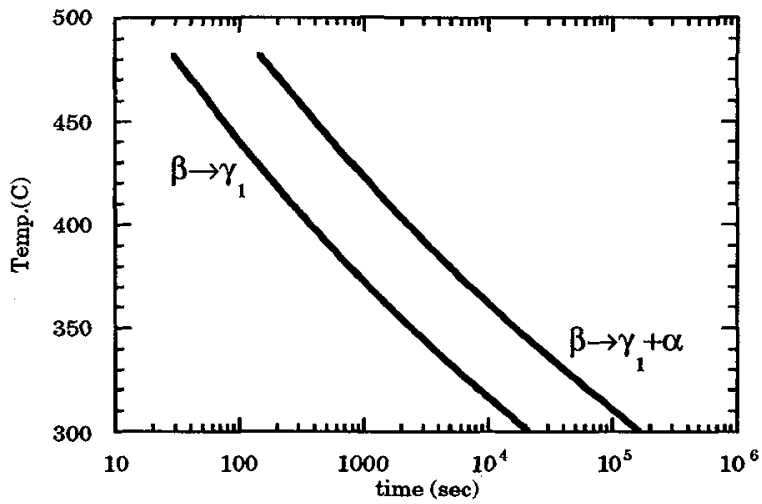

Fig 6. TTT curves of beginning of both precipitation processes obtained from their characteristic parameters.

\section{CONCLUSIONS}

The decomposition processes of the overcooled $\beta$ phase have been studied for a $\mathrm{Cu}-\mathrm{Al}-\mathrm{Ni}$ shape memory alloy. Two successive processes have been identified, the first one the pro-eutectoid $\gamma_{1}$ precipitation and the second one the $\beta \rightarrow \gamma_{1}+\alpha$ eutectoid decomposition. These kinetics have been fitted to a double Jhonson-Mhell-Avrami equation and the parameters of the kinetics have been obtained. By extrapolation of these parameters the kinetics at lower temperatures have been predicted. Thus we can determine the maximum using temperature before precipitation. This knowledge is very interesting in 
shape memory alloys, from a technological point of view, because the working use temperature is limited by the ageing precipitation processes which damage the martensitic transformation.

\section{Acknowledgements}

This work has been carried out with the financial support of the Spanish "Comision Interministerial de Ciencia y Tecnologia" (CICYT) in the framework of the "Plan Nacional de Materiales" (Project number MAT 92-0353) and the "Universidad del Pais Vasco" (Project number UPV EB049/95).

\section{References}

[1] H. Funakubo, "Shape Memory Alloys", Precision Machinery and Robotics Vo.1, Gordon and Breach Science Publishers, New York (1987).

[2] "Engineering Aspects of Shape Memory Alloys", Ed. by T.W. Duerig, K.N. Melton, D. Stöcked and C. M. Wayman, Butterworth-Heinemann Ltd, London (1990).

[3] L. Delaey, "Difusionless Transformation" in Phase Transformation in Materials, Ed. P. Haasen, VCH, Weinheim, Germany, (1991) pp. 339-404.

[4] V. Recarte, J. Herreros, M. L. Nó, J. San Juan; Materials Science Forum, 119, 323 (1991).

[5] V. Recarte, J. San Juan, J. Herreros, M. L. Nó; J. de Physique IV, 1, C4-271 (1991).

[6] V. Recarte, I. Hurtado, J. Herreros, M. L. Nó, J. San Juan, Scripta Mater., 34, 255 (1996).

[7] R. Thomson, J. O. Edwards; A F S Transactions Proc. 82nd Annual Conf., 15A, 385 (1978).

[8] Metals Handbook, vol. 8, 8Th Edition, A. S. M., Metals Park, Ohio, U.S.A. (1978).

[9] P. Brezina; Int. Metals Rev., 27, 77 (1982).

[10] Binary Alloy Phase Diagrams, Ed. T. B. Massalski, A. S. M. (1986).

[11] Ternary Alloys, vol. 4, Ed. G. Petzow and G. Effenberg, VCH,Weinheim, Germany (1991).

[12] W. A. Jhonson, R. F. Mhel; Trans. AMME, 135, 416 (1939).

[13] M. Avrami; J. Chem. Phys., 7, 1103 (1939).

[14] J. W. Christian; "The Theory of Transformation in Metals and Alloys", Pergamon Press, Oxford (1975).

[15] F. Cardellini, V. Contini, G. Mazzone; Scripta Metall. et Mater., 32, 641 (1995).

[16] E. J. Mittemeijer, A. Van Gent, P. J. Van der Schaaf; Metallurgical Transactions A, 17A, 1441 (1986).

[17] E. S. Lee, Y. G. Kim; Acta Metall. et Mater., 38, 1669 (1990).

[18] E. S. Lee, Y. G. Kim; Acta Metall. et Mater., 38, 1677 (1990)

[19] V. Recarte, Ph. D. Thesis, Univ. País Vasco, Bilbao (1997). 